\title{
COMPOSIÇÃO QUÍMICA E DEGRADABILIDADE RUMINAL DE FORRAGENS E SUBPRODUTOS AGROINDUSTRAIS NA REGIÃO OESTE DO PARANÁ
}

\author{
CERMICAL COMPOSITION AND RUMEN DEGRADABILITY OF FODDER AND \\ BY-PRODUCTS OF AGROINDUSTRIES IN WEST REGION PARANÁ
}

\section{Leiliane Cristine de SOUZA'; Maximiliane Alavarse ZAMBOM²; Simoni GUNDT ${ }^{3}$; Michele PASQUALOTTO ${ }^{4}$; Geraldo Tadeu dos SANTOS ${ }^{5}$; Deise Dalazen CASTAGNARA ${ }^{6}$; Daniele Cristina da Silva KAZAMA ${ }^{7}$}

1. Doutoranda no Programa de Pós Graduação em Zootecnia, Universidade Estadual de Maringá, UEM, PR, Brasil. leilics@ hotmail.com; 2. Professora, Doutora, Centro de Ciências Agrárias, Universidade Estadual do Oeste do Paraná, UNIOESTE, PR, Brasil; 3. Graduanda Zootecnia, UNIOESTE, PR, Brasil; 4. Mestranda do Programa de Pós Graduação em Zootecnia, UNIOESTE, PR, Brasil; 5. Professor, Doutor, Departamento de Zootecnia, UEM, PR, Brasil; 6. Pós Doutoranda, UNIOESTE, PR, Brasil; 7. Professora, Doutora, Departamento de Zootecnia e Desenvolvimento Rural, Universidade Federal de Santa Catarina, UFSC, Brasil.

RESUMO: Objetivou-se determinar a composição bromatológica e a degradabilidade de forragens e subprodutos agroindustriais comumente utilizados na Região Oeste do Paraná. Os alimentos avaliados foram o capim Sudão, os fenos de alfafa, de aveia preta, de azevém e de tifton 85, além da leucena, titônia, resíduo úmido de fécula de mandioca (RUFM), levedura de cana, resíduo úmido de cervejaria (RUC), misturão®, quirera de milho, resíduo de biscoito e resíduo de macarrão. Os alimentos foram analisados quanto aos teores de matéria seca (MS), matéria orgânica (MO), proteína bruta (PB), fibra em detergente neutro (FDN), e a digestibilidade in vitro da matéria seca (DIVMS), da parede celular (DIVPC) dos alimentos coletados na região. A partir das características analisadas foi possível agrupar os alimentos em volumosos: capim sudão, leucena, titônio, fenos de tifton, aveia preta, azevém e alfafa, e o RUFM; energéticos: misturão®, quirera de milho, resíduo de biscoito e resíduo de macarrão; proteicos: levedura de cana e RUC. Todos os alimentos estudados possuem potencial para utilização na alimentação de ruminantes, no entanto são necessários maiores estudos para a definição de critérios na utilização desses alimentos para o rebanho leiteiro, dentro de cada categoria. cervejaria.

PALAVRAS-CHAVE: Digestibilidade in vitro. Degradabilidade in situ. Alimentação. Resíduo úmido de

\section{INTRODUÇÃO}

Em sistemas de produção de ruminantes a diminuição das áreas de pastagem para o cultivo de oleaginosas e cereais e a estacionalidade na produção de forragens (FREITAS et al., 2002), limitam a disponibilidade de alimentos, especialmente os volumosos. Essa limitação contribui para elevar os custos de produção e diminuir a produtividade dos rebanhos, porém, poderia ser minimizada por meio do planejamento forrageiro.

Como estratégias para o planejamento podem ser utilizadas forrageiras diferenciadas das tradicionais para a região, a conservação do excedente da produção de forragens na forma de silagem ou feno (FREITAS et al., 2002) e o uso de fontes alimentares alternativas como os resíduos da agroindústria (SOUZA et al., 2012).

No oeste do Paraná algumas propriedades se destacam na produção de feno de Tifton 85 (CASTAGNARA et al., 2011), porém os fenos e Aveia Preta (CASTAGNARA et al., 2012a),
Azevém (NERES et al., 2011) e Alfafa (NERES et al., 2010) são menos usuais. Da mesma forma, o Capim Sudão (Sorghum bicolor), cv. Sudanense, e as leguminosas Leucena (Leucaenaleucocephala), e Titônio (Tithoniadiversifolia) são utilizadas apenas pontualmente por alguns produtores da região. A modesta utilização dessas fontes de volumosos deve-se à escassez de informações sobre a sua composição quando produzidas sob as condições edafoclimáticas regionais, limitando sua inclusão no balanceamento das dietas dos animais.

Situação semelhante é encontrada para os resíduos agroindustriais produzidos na região Oeste do Paraná, os quais já foram abordados em estudos científicos (NUNES et al., 2001; ABRAHÃO et al., 2006; GERON et al., 2007; ARRUDA et al., 2009) conduzidos em outras regiões brasileiras. Em se tratando da região Oeste, a predominância das atividades agrícolas possibilitou a instalação de diversas agroindústrias (OLIVEIRA et al., 2007), as quais são responsáveis pela geração dos resíduos agroindustriais como a massa de mandioca, levedura de cana, resíduo úmido de cervejaria, misturão®, 
quirera de milho, resíduo de biscoito e resíduo de macarrão.

Como a disponibilidade desses resíduos é constante e as condições edafoclimáticas possibilitam uma produção forrageira alternada entre tropicais e temperadas estável ao longo do ano, a inclusão desses alimentos nas dietas animais pode reduzir consideravelmente os custos de produção de ruminantes na região Oeste do Paraná. Essa possibilidade torna-se ainda mais promissora ao se considerar a capacidade digestiva de utilização de alimentos ricos em celulose e hemicelulose apresentada pelos ruminantes (ZAMBOM, et al., 2008).

Porém, para que a inclusão desses alimentos em dietas animais seja realizada com precisão e segurança, é necessário o conhecimento de sua composição bromatológica. No balanceamento das dietas podem ser considerados ainda a digestibilidade in vitro da matéria seca e da parede celular a degradabilidade in situ da matéria seca e da matéria orgânica desses alimentos.

Nesse contexto, objetivou-se com o presente estudo determinar a composição bromatológica, a digestibilidade in vitro da matéria seca e da parede celular e a degradabilidade in situ da matéria seca e da matéria orgânica de forragens e de resíduos agroindustriais utilizados na alimentação de ruminantes no Oeste do Paraná.

\section{MATERIAL E MÉTODOS}

As análises bromatológicas foram realizadas no Laboratório de Análise de Alimentos e Nutrição Animal do Departamento de Zootecnia da UNIOESTE, campus Marechal Cândido Rondon $\mathrm{PR}$, enquanto o ensaio de digestibilidade in vitro foi conduzido no Laboratório de Metabolismo Animal do Departamento de Zootecnia e o ensaio de degradabilidadein situ foi realizado na Fazenda Experimental de Iguatemi, ambos pertencentes a Universidade Estadual de Maringá, Maringá-PR.

Os alimentos avaliados foram obtidos diretamente nas propriedades rurais da Região Oeste do Paraná. As forragens frescas estudadas foram o Capim Sudão (Sorghum bicolor), cv. Sudanense, a Leucena (Leucaena leucocephala) e a Titônia (Tithonia diversifolia). Para estudo dos fenos foram coletados feno de Alfafa (Medicago sativa), Aveia Preta (Avena strigosa), Azevém (Lolium multiflorum) e capim Tifton 85 (Cynodon spp.). Os subprodutos agroindustriais amostrados foram $\mathrm{O}$ resíduo úmido de fécula de mandioca (Manihot esculenta Crantz) (RUFM), levedura de cana (Saccharomyces cerevisiae), resíduo úmido de cervejaria (RUC), Misturão®, quirera de milho e resíduos de biscoito e de macarrão.

Após as coletas, as amostras foram secas em estufa com ventilação forçada de ar por 72 horas a $55^{\circ} \mathrm{C}$, moída em moinho tipo "Willey" em peneira com crivo de $1 \mathrm{~mm}$ para determinação químico bromatológica dos teores de matéria seca (MS), de cinzas e de proteína bruta (PB), segundo metodologias descritas em Silva e Queiroz (2002) e de fibra em detergente neutro (FDN), segundo Van Soest et al., (1991). A matéria orgânica (MO) foi estimada pela diferença do teor de cinzas em relação a matéria seca.

Foi determinada a digestibilidade in vitro da matéria seca (DIVMS) e da digestibilidadein vitro da parede celular (DIVPC) adotando-se a técnica descrita por Tilley e Terry (1963) adaptada ao rúmen artificial, desenvolvida pela ANKON, conforme metodologia descrita por Holden (1999). As amostras foram incubadas na quantidade de 0,25 $\mathrm{g}$ de amostra dos alimentos pré secos e triturados, os quais foram colocados em filtros F57 da ANKOM e acondicionados em jarros de vidro contendo líquido de rúmen e solução tampão (HOLDEN, 1999).

Para a incubação as forrageiras foram agrupadas em gramíneas ou leguminosas enquanto os resíduos foram incubados separa :e nos jarros do equipamento Daisy Incubator. $v$ ı́́quido ruminal utilizado foi coletado de uma vaca (Holandesa), multípara, seca, com peso vivo de 550 $\mathrm{kg}$, munida de cânula ruminal. $\mathrm{O}$ animal foi mantido em piquete de grama estrela (Cynodon nlemfuensis), recebendo suplementação alimentar com concentrado, silagem de milho e mistura mineral.

Antes de ser inoculado nos jarros, o líquido ruminal foi homogeneizado em liquidificador, préaquecido a $39^{\circ} \mathrm{C}$, durante 30 segundos. Após, foi filtrado e espremido à mão em tecido de algodão, até a obtenção de $400 \mathrm{~mL}$ de líquido ruminal por jarro. Adicionou-se $\mathrm{CO}_{2}$ ao recipiente que recebeu o inóculo, ao liquidificador antes de ser usado, e também em cada jarro durante 30 segundos. Em seguida foi adicionada a solução tampão, $1600 \mathrm{~mL}$ em cada jarro, os sacos e o inóculo. Após, os jarros foram fechados com tampa dotada de válvula para escape de gases. A temperatura foi mantida em $39^{\circ} \mathrm{C}$, e os sacos-filtro foram incubados por 48 horas nos jarros da Incubadora in vitro (TE-150, da Tecnal®) (HOLDEN, 1999).

Para a DIVMS, foi adicionado $40 \mathrm{~mL}$ de $\mathrm{HCl} 6 \mathrm{~N}$ e $8 \mathrm{~g}$ de Pepsina em cada jarro, mantendo-se o material por mais 24 horas. A Pepsina foi previamente dissolvida em $34 \mathrm{~mL}$ de água destilada, a $35^{\circ} \mathrm{C}$, durante 5 minutos em agitador e, em seguida, feita a observação do valor do $\mathrm{pH}(2,5$ a 
3,0) no jarro. Decorridas as 24 horas de incubação sob $\mathrm{pH}$ 2,5 a 3,0 na presença de pepsina, os jarros foram drenados e os sacos lavados com água destilada até total retirada do material aderente. Os mesmos também secos em estufa de $105^{\circ} \mathrm{C}$, por 24 horas, para secagem definitiva e determinação da digestibilidade in vitro da matéria seca (DIVMS) (HOLDEN, 1999). Esta foi calculada pela diferença entre o alimento incubado e o resíduo que ficou após a incubação:

DIVMS $=($ MS do alimento incubado - MS do resíduo)/MS do alimento incubado * 100

Para determinação da DIVPC, adotou-se a metodologia descrita por Goering e Van Soest (1975), a qual requer a metade do tempo da técnica descrita por Tilley e Terry (1963). A DIVPC foi calculada pela diferença entre a quantidade que foi incubada e o resíduo que ficou após a análise de FDN do material incubado, através da fórmula:

DIVPC $=($ FDN do alimento incubado -

FDN do resíduo)/ FDN do alimento incubado $* 100$

$\mathrm{O}$ delineamento experimental adotado foi o inteiramente casualizado, com três repetições por tratamento. As repetições foram as três coletas (semanas), e os tratamentos os três grupos de alimentos (volumoso, protéico e energético). Os efeitos dos tratamentos foram estudados através da análise de variância e os contrastes de médias pelo teste de Tukey. As análises dos dados foram analisadas seguindo o modelo:

$$
Y_{i l k}=\mu+A_{i}+C_{j}+A C_{i j}+e_{i j k}
$$

Em que: $\mathbf{Y}_{\text {ikk }}=$ é o valor referente ao alimento $i$, na coleta $j$ e repetição k dentro de cada coleta; $\boldsymbol{\mu}=$ efeito da média geral; $\mathbf{A}_{\mathbf{i}}=$ efeito do alimento i, i= 1, 2, 3 e 4; $\mathbf{C}_{\mathbf{j}}=$ efeito da coleta $\mathrm{j}, \mathrm{j}=1,2$, 3 e $4 ; \mathbf{A C}_{\mathrm{ij}}=$ efeito da interação: alimento i versus coleta $\mathbf{j} ; \mathbf{e}_{\mathbf{i j k}}=$ é o erro experimental, associado a cada observação $Y_{\text {ilk. }}$.

Foi determinada a degradabilidade do Titônio, massa de mandioca e feno de aveia preta, sendo estimada pela técnica in situ do saco de náilon.

As amostras a serem incubadas foram pré secas em estufa de $55^{\circ} \mathrm{C}$ por 72 horas e moídas em peneira com crivo de $5 \mathrm{~mm}$. Foram colocados sete gramas de amostra em cada saco de náilon. No momento da incubação, os sacos foram presos em duplicata para os tempos de incubação $0,3,6,12$ e 24 e em triplicata para os tempos 48, 72, 96 e 120 horas, a uma barra cilíndrica de ferro, com aproximadamente $450 \mathrm{~g}$ presa por um fio de náilon de $50 \mathrm{~cm}$ de comprimento à cânula ruminal.

Para avaliar a degradabilidade ruminalin situ da MS e da MO foram utilizadas três vacas (Holandesa), multíparas, com peso vivo de $550 \mathrm{~kg}$, munidas de cânula ruminal. Os animais foram mantidos em piquetes de grama estrela (Cynodon nlemfuensis), recebendo suplementação alimentar com ração concentrada, silagem de milho e mistura mineral.

Após o período de incubação, os sacos de náilon foram removidos e lavados em água corrente para completa retirada das impurezas externas, em seguida foram congelados, para posterior secagem, pesagem e análises. No final de todo o período de incubação os sacos foram submetidos à secagem em estufa de ventilação forçada a $55^{\circ} \mathrm{C}$, por 72 horas e, posteriormente os subprodutos foram analisados quanto aos teores de MS e MO para a determinação da taxa de desaparecimento destes.

A porcentagem de desaparecimento em cada tempo foi calculada pela proporção que permaneceu nos sacos após a incubação no rúmen. A degradabilidade ruminal da MS e da MO calculada pela equação descrita por Orskov e McDonald (1979):

$$
\mathrm{p}=\mathrm{a}+\mathrm{b}\left(1-\mathrm{e}^{-\mathrm{ct})}\right.
$$

Onde: $\mathbf{p}=$ taxa de degradação potencial no tempo $t ; \mathbf{a}=$ porção prontamente solúvel no rúmen (representado pelo intercepto da curva de degradação no tempo 0);b = fração insolúvel, mas potencialmente degradável; $\mathbf{c}=$ taxa constante de degradabilidade da fração $\mathrm{b}$; $\mathbf{e}=$ logaritmo natural, que representa o tempo de colonização dos microrganismos das partículas dos alimentos, para o início da degradação microbiana (lag time); $\mathbf{t}=$ tempo de incubação.

Os parâmetros não-lineares $\mathrm{a}, \mathrm{b}$ e c foram estimados pelos procedimentos iterativos de quadrados mínimos. A degradabilidade efetiva (DE) da MS e da MO no rúmen foi calculada pela equação descrita por Orskov e McDonald (1979):

$$
\mathrm{DE}=\mathrm{a}+((\mathrm{b} \times \mathrm{c}) /(\mathrm{c}+\mathrm{k}))
$$

Onde: $\mathbf{k}=$ representa a taxa estimada da passagem dos sólidos no rúmen, e os demais parâmetros foram descritos na equação anterior.

As degradabilidades efetivas foram estimadas para cada tratamento, levando-se em conta as taxas de passagem de sólidos no rúmen de: $2 \% / \mathrm{h}, 5 \% / \mathrm{h}$ e $8 \% / \mathrm{h}$, as quais podem ser atribuídas aos níveis de ingestão alimentar, baixa, média e alta (AFRC, 1993).

Os dados obtidos foram submetidos à análise de variância, utilizando o SAEG (1997), e as médias comparadas pelo teste Tukey a $5 \%$ de significância.

\section{RESULTADOS E DISCUSSÃO}

Os teores de matéria seca (MS), matéria orgânica (MO), proteína bruta (PB), fibra em detergente neutro (FDN) e a digestibilidade in vitro da matéria seca e da parede celular dos alimentos, estão apresentados na Tabela 1, agrupados como alimentos volumosos, energéticos e protéicos. 
O capim Sudão apresentou teores de PB de $72,3 \mathrm{~g} / \mathrm{kg}$ de PB aos 60 dias de rebrota, o qual pode ser considerado baixo se comparado com o obtido por Tomich et al. (2006), que constataram 144,6 $\mathrm{g} / \mathrm{kg}$ de PB em plantas com idade de rebrota de 30 dias. Altos valores de FDN também são encontrados em forrageiras tropicais, especialmente em estádio avançado de desenvolvimento como o capim Sudão estudado neste ensaio (Tabela 1), que apresentou valores de FDN de 709,9 $\mathrm{g} / \mathrm{kg}$, superando os observados em outros estudos (TOMICH et al., 2003; 2004; 2006). No entanto, os valores obtidos para PB e FDN não interferiram na DIVMS, porém foram os responsáveis pela baixa DIVPC observada para o capim Sudão, pois segundo Van Soest (1994) as características da parede celular são mais importantes na regulação da digestibilidade do que as proporções desses componentes.

Tabela 1. Composição químico-bromatológica dos alimentos volumosos, energéticos e proteicos.

\begin{tabular}{|c|c|c|c|c|c|c|}
\hline Alimentos & MS (g/kg) & MO (g/kg) & $\mathrm{PB}(\mathrm{g} / \mathrm{kg})$ & $\begin{array}{l}\text { FDN } \\
(\mathrm{g} / \mathrm{kg})\end{array}$ & $\begin{array}{c}\text { DIVMS } \\
\%\end{array}$ & $\begin{array}{c}\text { DIVPC } \\
\%\end{array}$ \\
\hline \multicolumn{7}{|l|}{ Volumosos } \\
\hline Capim Sudão & 222,0 & 934,5 & 72,3 & 709,9 & $63,30 \mathrm{~b}$ & $33,48 \mathrm{e}$ \\
\hline Leucena & 293,0 & 933,8 & 174,9 & 451,0 & $64,73 \mathrm{c}$ & $42,61 \mathrm{de}$ \\
\hline Titônio & 911,6 & 922,3 & 140,9 & 489,0 & - & - \\
\hline Feno de Tifton & 933,0 & 934,2 & 96,6 & 710,1 & $58,27 \mathrm{c}$ & $50,60 \mathrm{c}$ \\
\hline Feno de Aveia Preta & 913,1 & 918,8 & 98,0 & 687,1 & $61,43 b c$ & $54,46 b$ \\
\hline Feno de Azevém & 912,2 & 942,6 & 106,1 & 647,7 & $59,21 \mathrm{c}$ & $47,32 d$ \\
\hline Feno de Alfafa & 894,7 & 930,4 & 181,5 & 430,3 & $60,31 b c$ & $47,07 d$ \\
\hline Massa de Mandioca & 114,8 & 980,1 & 15,6 & 452,2 & $85,5 \mathrm{a}$ & $72,69 a$ \\
\hline \multicolumn{7}{|l|}{ Energéticos } \\
\hline Misturão® & 910,9 & 942,9 & 129,2 & 294,8 & $85,26 b$ & $67,13 b$ \\
\hline Quirera de Milho & 910,0 & 981,1 & 84,1 & 148,7 & $94,17 \mathrm{a}$ & - \\
\hline Resíduo de Biscoito & 958,6 & 991,5 & 97,4 & 160,9 & $95,32 \mathrm{a}$ & $92,69 a$ \\
\hline Resíduode Macarrão & 945,6 & 977,9 & 103,3 & 12,8 & $95,76 \mathrm{a}$ & - \\
\hline \multicolumn{7}{|l|}{ Proteicos } \\
\hline Levedura de Cana & 922,7 & 930,8 & 379,1 & 1,16 & $95,86 a$ & - \\
\hline RUC $^{1}$ & 239,6 & 977,4 & 235,0 & 65,65 & $59,62 \mathrm{~b}$ & 48,99 \\
\hline $\mathrm{CV}(\%)$ & - & - & - & - & 8,50 & 7,14 \\
\hline
\end{tabular}

${ }^{1}$ RUC: Resíduo úmido de cervejaria; Médias seguidas de mesma letra minúscula na coluna não diferem estatisticamente entre si pelo teste Tukey ao nível de 5\% de probabilidade.

A leucena e o titônio apresentaram elevado conteúdo de $\mathrm{PB}$ e reduzido conteúdo de FDN quando comparadas ao capim Sudão, no entanto, os valores de digestibilidade da leucena se mantiveram próximos aos observados para as gramíneas analisadas neste trabalho (Tabela 1). Em se tratando dos fenos, os valores obtidos para os fenos de Tifton 85, Aveia Preta, Azevém e Alfafa são coerentes com os observados em outros estudos (NERES et al., 2010; CASTAGNARA et al., 2011; CASTAGNARA et al., 2012b).

Apesar das diferenças observadas para os valores de PB, todas as forragens estudadas poderiam ser utilizadas sem restrições na alimentação de ruminantes, pois apresentaram teores de PB superiores ao intervalo crítico de $60-80 \mathrm{~g} / \mathrm{kg}$ na MS recomendado por Van Soest (1994). Segundo o autor, esses valores mínimos são necessários para que não ocorra a diminuição na eficiência do crescimento microbiano $\mathrm{e}$ na capacidade de degradação da fibra devido ao balanço nitrogenado negativo (VAN SOEST, 1994). Entretanto os valores de FDN observados para todas as gramíneas estudadas limitam a sua utilização como única fonte de nutrientes nas dietas, pois estes superam o limite recomendado de $550-600 \mathrm{~g} / \mathrm{kg}$ da MS. Segundo Mertens (1994) forragens com mais de $600 \mathrm{~g} / \mathrm{kg}$ de FDN ocasionam redução do consumo voluntário de matéria seca devido ao efeito de enchimento ocasionado no rúmen (MERTENS, 1994).

As leguminosas apresentaram conteúdo de FDN inferior à $600 \mathrm{~g} / \mathrm{kg}$, porém, os valores de DIVMS e DIVPC se equivaleram entre as forragens, com exceção para o capim Sudão que apresentou 
DIVPC inferior. Os valores obtidos são considerados baixos especialmente devido à correlação negativa existente entre a FDN e a digestibilidade (ALVES DE BRITO et al., 2003). Baixos valores de digestibilidade são frequentes em forrageiras tropicais (GERDES et al., 2000), e devem-se ao aumento nas porcentagens de moléculas orgânicas não-nitrogenadas (VAN SOEST, 1994) como a celulose, hemicelulose e lignina (REIS et al., 2005) e redução na concentração de compostos nitrogenados (VAN SOEST, 1994) e potencialmente digestíveis como os carboidratos solúveis, proteínas, minerais e vitaminas (REIS et al., 2005). Da mesma forma que para a FDN, os valores obtidos para DIVMS e DIVPC sugerem cautela na utilização das forragens abordadas nesse estudo em dietas animais, pois a redução da digestibilidade ocasiona aumento do tempo de retenção da ingesta no rúmen com redução no consumo de matéria seca ocasionando efeitos diretos sobre o desempenho animal (REZENDE et al., 2012).

A massa de mandioca apesar do baixo conteúdo de FDN é considerada alimento volumoso por apresentar também baixo conteúdo de PB (AFRC, 1996), e neste estudo apresentou elevados coeficientes de DIVMS e DIVPC. Os valores da composição bromatológica e DIVMS e DIVPC observados na massa de mandioca divergem dos obtidos em outros trabalhos (FERREIRA et al., 2007; SILVEIRA et al., 2002) que também contemplaram a avaliação desse resíduo. Essas diferenças devem-se ao tipo de processamento empregado em cada indústria e por esse motivo recomenda-se aos pecuaristas a aquisição do resíduo de indústrias que adotem o mesmo tipo processamento, e se possível a realização de análises bromatológicas periódicas para o conhecimento da composição exata desse resíduo antes de sua inclusão nas dietas dos animais.

O Misturão® apresentou conteúdo de PB numericamente superior à quirera de milho, resíduo de boscoito e resíduo de macarrão, no entanto, FDN superior e digestiblidade inferior. Sua composição deve-se ao seu constituinte principal, que é o resíduo de varredura da indústria de farinhas de trigo. Apesar das diferenças em comparação com os outros alimentos, o Misturão ${ }^{\circledR}$ pode ser uma alternativa interessante para produtores de regiões com disponibilidade desse subproduto especialmente devido ao seu baixo custo de aquisição em relação à outros alimentos convencionalmente utilizados. No entanto, a utilização do Misturão ${ }^{\circledR}$ nas dietas animais deve ser criteriosa, pois assim como outros subprodutos da agroindústria, sua composição pode variar significativamente havendo a necessidade de sua caracterização bromatológica periodicamente.

A quirera de milho manteve suas características próximas às descritas por Valadares Filho (2000), inclusive para o coeficiente de DIVMS, que segundo resultados do autor é próximo à $900 \mathrm{~g} / \mathrm{kg}$, indicando a alta digestibilidade deste alimento.

Os resíduos de biscoito e macarrão apresentaram conteúdos de $\mathrm{PB}$ limitados, no entanto, compensados por elevados coeficientes de DIVMS e DIVPC (Tabela 1). Esses subprodutos são obtido em indústrias de biscoitos e macarrão e compreendem a varredura da linha de produção, bem como os produtos finais reprovados nos teses de qualidade do produto destinado ao consumidor por imperfeições. Em trabalho conduzido com resíduo de panificação e com redíduos de biscoitos, Passini et al. (2001) e Nunes et al. (2001) obtiveram conteúdos de MS e PB semelhantes aos resultados aqui obtidos. Os autores obtiveram valores de 931,4 e $924,2 \mathrm{~g} / \mathrm{kg}$ de MS e 92,4 e $83,8 \mathrm{~g} / \mathrm{kg}$ de PB, respectivamente. Devido à sua maior uniformidade, o resíduo de biscoito é um alimento promissor para utilização em dietas animais, especialmente para bovinos leiteiros, no entanto, ainda são escassos os trabalhos que contemplaram a inclusão em dietas de ruminantes.

A levedura de cana é utilizada nos processos de fermentação do caldo extraído da cana-de-açúcar para sua fermentação e produção de álcool (GRANGEIRO et al., 2001) e tradicionalmente possui uma quantidade elevada de PB. No presente estudo, a levedura de cana também apresentou conteúdo de PB elevado $(379,1 \mathrm{~g} / \mathrm{kg})$ concordando com os resultados observados por Sampaio et al. (1996) que observaram valores médios de 307,7 $\mathrm{g} / \mathrm{kg}$ de PB.

Os teores médios de MS observados para o RUC encontram-se dentro da faixa descrita na literatura por diversos autores, a qual compreende valores de $9 \%$ a 30\% (LÓPES E PASCUAL, 1981; CARDOSO et al., 1982; SOUZA et al., 2012). A amplitude dos conteúdos de MS deve-se principalmente às diferenças constatadas pela diversidade de processamentos utilizados nas agroindústrias. Os teores médios encontrados para a PB indicam o grande potencial deste resíduo para utilização como fonte proteica na alimentação animal, especialmente para ruminantes e em regiões onde estão localizadas as indústrias produtoras de cerveja.

Os coeficientes de DIVMS de 59,62\% e da DIVPC 48,99\% do RUC foram superiores aos 
observados por Geron et al. (2007), que verificaram valores de DIVMS de $42,1 \%$ e 43,5\% para o RUC e para o RUC fermentado, respectivamente. Estudando a qualidade fermentativa de silagens de resíduo úmido de cervejaria Souza et al., (2012) observaram valores semelhantes aos obtidos neste estudo. Segundo Geron et al. (2007) a menor digestibilidade do RUC comparada ao do farelo de soja deve-se aos menores teores de carboidratos não estruturais que os subprodutos apresentaram e aos maiores valores de FDN e FDA.

O Titônio apresentou maiores valores da fração prontamente solúvel (a) e degradabilidade efetiva (DE) na matéria seca (MS) em relação aos demais alimentos avaliados (Tabela 2) devido à sua composição química, que possuía valores de FDN inferiores aos demais alimentos volumosos estudados. O maior desaparecimento ruminal da MS do Titônio também pode estar relacionada com a maior presença de compostos solúveis em água em relação a taxa de passagem de $5 \% / \mathrm{h}$ e $8 \% / \mathrm{h}$.
Já o RUFM apresentou resultados significativos superiores para a fração insolúvel, mas potencialmente degradável (b) na MS e na MO quando comparado ao feno de aveia preta. Essas diferenças devem-se ao processamento industrial para extração do amido ao qual a mandioca é submetida, ocasionando a geração do RUFM. Prado et al. (2004) trabalhando com degradabilidade in situ da massa de mandioca não obteve diferença estatística com relação a DE $(2 \%, 5 \%, 8 \% / \mathrm{h})$ apresentando valores de $65,6 \%, 52,6 \%$ e $46,9 \%$, respectivamente. $\mathrm{O}$ conhecimento da DE e DP do RUFM é fundamental no balanceamento de dietas de ruminantes devido à composição desse alimento. $\mathrm{O}$ alto conteúdo de amido presente no RUFM (JASKO et al., 2011) devido à baixa eficiência média do processo de extração adotado nas indústrias, por isso as dietas com inclusão de RUFM devem ser criteriosamente balanceadas.

Tabela 2. Parâmetros de degradação ruminal do titônio (TIT), resíduo úmido de fécula de mandioca (RUFM) e feno de aveia preta (FAP)

\begin{tabular}{lcccc}
\hline \multirow{2}{*}{ VARIÁVEIS } & \multicolumn{4}{c}{ TRATAMENTOS } \\
\cline { 2 - 5 } \multicolumn{1}{c}{ Matéria Seca (MS) } & TIT & RUFM & FAP & CV\% \\
\hline a & $43,79 \mathrm{a}$ & $9,57 \mathrm{~b}$ & $24,83 \mathrm{~b}$ & 28,55 \\
$\mathrm{~b}$ & $58,01 \mathrm{~b}$ & $76,20^{\mathrm{a}}$ & $40,06 \mathrm{c}$ & 10,03 \\
$\mathrm{c}$ & $0,02 \mathrm{a}$ & $0,05^{\mathrm{a}}$ & $0,05^{\mathrm{a}}$ & 64,03 \\
DP\% & $101,8 \mathrm{a}$ & $85,77^{\mathrm{a}}$ & $64,89 \mathrm{~b}$ & 8,69 \\
DE (2\%/h) & $73,72 \mathrm{a}$ & $62,29 \mathrm{~b}$ & $49,37 \mathrm{c}$ & 5,64 \\
DE (5\%/h) & $61,36 \mathrm{a}$ & $45,90 \mathrm{~b}$ & $41,64 \mathrm{~b}$ & 8,17 \\
DE (8\%/h) & $56,25 \mathrm{a}$ & $37,35 \mathrm{~b}$ & $37,84 \mathrm{~b}$ & 9,93 \\
\hline \multicolumn{1}{c}{ Matéria Orgânica (MO) } & & & & \\
\hline $\mathrm{a}$ & $41,52 \mathrm{a}$ & $11,78 \mathrm{~b}$ & $21,71 \mathrm{~b}$ & 30,67 \\
$\mathrm{~b}$ & $56,29 \mathrm{ab}$ & $74,31^{\mathrm{a}}$ & $41,70 \mathrm{~b}$ & 13,69 \\
$\mathrm{c}$ & $0,03 \mathrm{a}$ & $0,05^{\mathrm{a}}$ & $0,05^{\mathrm{a}}$ & 65,28 \\
DP\% & $97,81 \mathrm{a}$ & $86,09^{\mathrm{a}}$ & $63,42 \mathrm{~b}$ & 9,56 \\
DE $(2 \% / \mathrm{h})$ & $73,51 \mathrm{a}$ & $63,14 \mathrm{~b}$ & $47,07 \mathrm{c}$ & 5,92 \\
DE (5\%/h) & $60,97 \mathrm{a}$ & $47,16 \mathrm{~b}$ & $39,12 \mathrm{~b}$ & 8,86 \\
DE (8\%/h) & $55,50 \mathrm{a}$ & $38,83 \mathrm{~b}$ & $35,23 \mathrm{~b}$ & 10,85 \\
\hline
\end{tabular}

a: fração prontamente solúvel; b: fração insolúvel, mas potencialmente degradável c: taxa constante de degradabilidade da fração b; DP: degradablidade potencial; DE: degradabilidade efetiva; CV: coeficiente de variação; Médias na mesma linha, seguidas de letras diferentes, diferem $(\mathrm{P}>0,05)$ pelo teste de Tukey $(5 \%)$.

A taxa constante de degradabilidade da fração b (c) e os valores de DP (\%) da MS e MO foram semelhantes no titônio no RUFM e inferiores no feno de aveia preta. Essas diferenças devem-se à composição desses alimentos, pois o feno de aveia preta apresentou conteúdo de FDN superior ao RUFM e ao titônio.

Apesar do feno de aveia preta apresentar altos valores de FDN $(68,71 \%)$ foi observado uma boa degradabilidade efetiva da MS $(49,37 \%$ a $2 \% / \mathrm{h})$ diminuindo com o aumento da taxa de passagem. 
Em trabalho realizado por Valadares Filho et al.(2001) com feno de Tifton 85 obteve-se valores para as frações a e b da MS de $17,67 \%$ e $53,36 \%$ respectivamente. Os resultados confirmam o potencial de utilização do feno de aveia preta para conservação de excedentes de forragem produzida durante o período hibernal no Oeste do Paraná, bem como de sua utilização na alimentação de ruminantes.

Nota-se que com o aumento da taxa de passagem ocorreu à diminuição da DE tanto na MS quanto a MO para todos os alimentos testados. Mostrando a importância da mensuração da degradabilidade no rúmen, considerando a taxa de passagem. Quando ambas não são mensuradas, pode-se subestimar a extensão da degradação, pois as partículas dos alimentos estarão sujeitas a passagem para o compartimento seguinte, antes de serem completamente degradadas (PIRES et al., 2006).

\section{CONCLUSÕES}

Todos os alimentos avaliados podem ser considerados como fonte alternativa na dieta dos ruminantes, necessitando de análises bromatológicas periódicas. No entanto, são necessárias avaliações para a definição de critérios de utilização desses alimentos para as diversas categorias do rebanho leiteiro.

\begin{abstract}
This study aimed to determine the chemical composition and degradability of forage and byproducts agroindustries commonly used in West Region Paraná. The foods studied were Sudan grass, the hay alfalfa, oats, ryegrass and Tifton 85 , and the leucaena, titônia, wet waste cassava starch (RSFM), sugar cane yeast, wet brewery's grain (RUC) compound ${ }^{\circledR}$, corn grits, cookies residue and noodlesresidue. Foods were analyzed for dry matter (DM), organic matter (OM), crude protein (CP), neutral detergent fiber (NDF) and in vitro dry matter digestibility (IVDMD), cell wall (IVDCW) food collected in the region. From of characteristics analyzed was possible to group into voluminous foods, sudan grass, leucaena, titônio, Tifton hay, oats, ryegrass and alfalfa, and RUFM; energy foods: compond®, corn grits, cookies residue and noodles residue; protein foods: yeast and RUC. All foods studied have potential for use in ruminant feed, however more studies are necessary to define the criteria for the use of these foods dairy herd, within each category.
\end{abstract}

KEY-WORDS: Wet brewery's waste. Food. in situ degradability. in vitro digestibility.

\title{
REFERÊNCIAS
}

ABRAHÃO, J. J. S.; PRADO, I. N.; PEROTTO, D.; ZEOULA, L. M.; LANÇANOVA, J. A. C.; LUGÃO, S. M. B. Digestibilidade de dietas contendo resíduo úmido de mandioca em substituição ao milho para tourinhos em terminação. Revista Brasileira de Zootecnia, Brasília, DF v. 35, n. 4, p. 512-518, 2006.

AGRICULTURAL AND FOOD RESEARCH COUNCIL-AFRC. Energy and protein requeriments of ruminants. Wallingford: Commonwealth Agricultural BureauxInternational. 159p, 1993.

AGRICULTURAL AND FOOD RESEARCH COUNCIL-AFRC, Necessidades energêticas y proteicas de losrumiantes, Acribia, Zaragoza, 175p, 1996.

ALVES DE BRITO, C. J. F.; RODELLA, R. A.; DESCHAMPS, F. C. Perfil químico da parede celular e suas implicações na digestibilidade de Brachiaria brizantha e Brachiaria humidicola. Revista Brasileira de Zootecnia, Brasília, DF v. 32, n. 8, p. 1835-1844, 2003.

ARRUDA, A. M. V.; RIBEIRO, L. B.; PEREIRA, E.S. Avaliação de alimentos alternativos para cavalos adultos da raça Crioulo. Revista Brasileira de Zootecnia, Brasília, DF, v. 38, n. 1, p. 61-68. 2009.

CASTAGNARA, D. D.; AMES, J. P.; NERES, M. A.; OLIVEIRA, P. S. R.; SILVA, F. B.; STANGARLIN, J. R.; FRANZENER, G. Use of conditioners in the production of Tifton 85 grass hay. Revista Brasileira de Zootecnia, Brasília, DF v. 40, n. 10, p. 2083-2090, Oct. 2011. 
CASTAGNARA, D. D.; NERES, M. A.; OLIVEIRA, P. S. R.; MEINERZ, C. C.; MESQUITA, E. E. Use of conditioning in the production of black and white oat hay using two cutting heights. Revista Brasileira de Zootecnia, Brasília, DF v. 41, n. 5, p. 1082-1092, 2012a.

CASTAGNARA, D. D.; NERES, M. A.; OLIVEIRA, P. S. R.; JOBIM, C. C.; TRÊS, T. T.; MESQUITA, E. E.; ZAMBOM, M. A. Use of a conditioning unit at the haymaking of Tifton 85 overseeded with Avena sativa or Lolium multiflorum. Revista Brasileira de Zootecnia, Brasília, DF v. 41, n. 6, p. 353-1359, 2012B.

CARDOSO. R. M.; SILVA, J. F. C.; MELLO, R. P.; MOTTA, V. A. F.; Produção de leite de vacas alimentadas com silagem de sorgo suplementada com polpa úmida de cevada. Revista da Sociedade Brasileira de Zootecnia, Brasília, DF v. 11, n. 1, p. 38-45, 1982.

FERREIRA, G. D. G.; OLIVEIRA, R. L.; CARDOSO, E. C.; MAGALHÃES, A. L. R.; BRITO, E. L. Valor Nutritivo de Co-produtos da Mandioca. Revista Brasileira Saúde Produção Animal, Salvador, BA v. 8, n. 4, p. 364-374, out/dez, 2007.

FREITAS, D.; COAN, R. M.; REIS, R. A.; PEREIRA, J. R. A.; PANIZZI, R. C. Avaliação de fontes de amônia para conservação do feno de alfafa (Medicago sativa) armazenado com alta umidade. Revista Brasileira de Zootecnia, Brasília, DF v. 31, n. 2, p. 866-874, 2002 (suplemento).

GERDES, L.; WERNER, J. C.; COLOZZA, M. T. et al. Avaliação de características de valor nutritivo das gramíneas forrageiras Marandu, Setária e Tanzânia nas estações do ano. Revista Brasileira de Zootecnia, Brasília, DF v. 29, n. 4, p. 955-963, 2000.

GERON, L. J. V.; ZEOULA, LM.; BRANCO, A. F. ERKE,J.A.; PRADO, O. P. JACOBI, G. Caracterização, fracionamento protéico, degradabilidade ruminal e digestibilidade in vitro da matéria seca e proteína bruta do resíduo de cervejaria úmido e fermentado. ActaScientiarum Animal Science, Maringa, PR v. 29, n. 3, p. 291299. 2007.

GOERING, H. K., VAN SOEST, P. J. Forage fiber analyses (apparatus, regents, procedures, and some aplications), Agriculture Handbook 379. United States Department of Agriculture. 20p., 1975.

GRANGEIRO, M. G. A.; FUENTES, M. F. F.; FREITAS, E. R.; ESPÍNDOLA, G. B.; SOUZA, F. M. Inclusão da Levedura de Cana-de-Açúcar (Saccharomycescerevisiae) em Dietas para Frangos de Corte, Revista Brasileira de Zootecnia, Brasília, DF v. 30, n. 3, p. 766-773, 2001.

HOLDEN, L. A. Comparision of methods of in vitro dry matter digestibility for ten feeds. Journal of Dairy Science, Oak St. Sul v. 2, n. 8, p. 1791-1794, 1999.

JASKO, A. C.; ANDRADE, J.; CAMPOS, F.P.; PADILHA, L.; PAULI, R.B.; QUAST, L.B.; SCHNITZLER, E.; DEMIATE, I.M. Caracterização físico-química de bagaço de mandioca in natura e após tratamento hidrolítico, Revista Brasileira de Tecnologia Agroindustrial, Ponta Grossa, PR v. 05, suplemento: p. 427441, 2011.

LÓPEZ, J. D.; PASCUAL, J. L. M. Influence of the drying process on the composition of brewers dried grains. Animal Feed Science and Technology, v. 6, p. 163-168, 1981. http://dx.doi.org/10.1016/03778401(81)90047-X

MERTENS, D. R. Regulation of forage intake. In: FAHEY JR., G. C. (Ed.). Forage quality, evaluation and utilization. Madison: American Society of Agronomy. p. 450-493, 1994.

NERES, M. A.; CASTAGNARA, D. D.; MESQUITA, E. E.; JOBIM, C. C.; TRÊS, T. T.; OLIVEIRA, P. S. R.; OLIVEIRA, A. A. M. A. Production of tifton 85 hay overseeded with white oats or ryegrass. Revista Brasileira de Zootecnia, Brasília, DF v. 40, n. 8, p. 1638-1644, Aug. 2011. 
NUNES, R. V.; ROSTAGNO, H. S.; ALBINO, L. F. T.; GOMES, P. C.; NASCIMENTO, A. H. Valores de aminoácidos digestíveis verdadeiros e equações de predição dos aminoácidos digestíveis do grão e de subprodutos do trigo para aves .Revista Brasileira de Zootecnia, Brasília, DF v. 30, n. 3, p. 774-784. 2001.

OLIVEIRA, M. A.; DONEGA, M. A.; PERALTA, R. M.; SOUZA, C. G. M. Produção de inóculo do cogumelo comestível Pleurotuspulmonarius (Fr.) Quélet - CCB19 a partir de resíduos da agroindústria, Ciência e Tecnologia em Alimentos, Campinas, SP v. 27(supl.): 84-87, ago. 2007.

ORSKOV, E. R., McDONALD, I. The estimation of protein degradability in the rumen from incubation measurements weighted acoording to rate of passage. Journal of Agricultural Science, Cambridge v. 92, p. 499-503, 1979. http://dx.doi.org/10.1017/S0021859600063048

PASSINI, R.; SPERS, A.; LUCCI, C. S. Efeitos da substituição parcial do milho na dieta pelo resíduo de panificação sobre desempenho de novilhos da raça Holandesa. Pesquisa Agropecuária Brasileira, Brasília, DF v.36, p.689-694, 2001.

PIRES, A. J. V.; REIS, R. A.; CARVALHO, G. G. P.; SIQUEIRA, G. R.; BERNADES, T. F.; RUGGIERI, A. C.; ALMEIDA, E. O.; ROTH, M. T. Degradabilidade ruminal da matéria seca, da fração fibrosa e da proteína bruta de forrageiras. Pesquisa Agropecuária Brasileira, Brasília, DF v. 41, n. 4, p. 643-648, 2006.

PRADO, I. N.,MOREIRA, F. B., ZEOULA, L. M., WADA, F. Y., MIZUBUTI, I. Y., NEVES, C. A. Degradabilidade in situ da matéria seca, proteína bruta e fibra em detergente neutro de algumas gramíneas sob pastejo contínuo. Revista Brasileira de Zootecnia, Brasília, DF v. 33, n. 5, p. 1332 - 1339, 2004.

REIS, R. A.; MELO G. M. P.; BERTIPAGLIA L. M. A. et al. Otimização da utilização da forragem disponível através da suplementação estratégica. In: REIS R. A.; SIQUEIRA, G.R.; BERTIPAGLIA, L. M. A. et al. (Eds.). Volumosos na produção de ruminantes. Jaboticabal, SP: Funep, p. 187-238.2005.

REZENDE,A. V.;SENEDESE,S. S.;RABELO,C. H. S.;NOGUEIRA, D. A.;VIEIRA, P. F.;RABELO, F. H. S. Composição química e digestibilidade in vitro da massa seca de cana-de-açúcar acrescida de ureia em diferentes tempos de estocagem. Revista Brasileira Saúde e Produção Animal, Salvador, BA v. 13, n. 1, p. $2534 \mathrm{jan} / \mathrm{mar}, 2012$.

SAEG - Sistema para análise estatística e genética, Versão 7.0,Viçosa, MG: Fundação Arthur Bernardes, 1997.

SAMPAIO, A. A. M. ; EZEQUIEL, J. M. B. ; OLIVEIRA, M. D. S. ; VIEIRA, P. F. . Matéria seca, cálcio e fósforo em rações para ovinos, contendo farelo de algodão, levedura e uréia. Pesquisa Agropecuária Brasileira, Brasília, DF, v. 31, n. 4, p. 301-304, 1996.

SILVA, D. J.; QUEIROZ, A. C. Análise de alimentos: métodos químicos e biológicos. $3^{\circ}$.ed. Viçosa, MG: Universidade Federal de Minas Gerais, 2002. 235p.

SILVEIRA, R. N.; BERCHIELLI, T. T.; FREITAS, D.; SALMAN, A. K. D.; ANDRADE, P.; PIRES, A. V.; FERNANDEZ, J. J. R. Fermentação e degrabilidade ruminal e bovinos alimentados com resíduos de mandioca e cana-de-açúcar ensilados com polpa cítrica peletizada. Revista Brasileira de Zootecnia, Brasília, DF v. 31, n. 2, p. 793-801, 2002.

SOUZA, L. C.; ZAMBOM, M. A.; POZZA, M. S. S.; NERES, M. N.; RADIS, A. C.; BORSATTI, L.; CASTAGNARA, D. D.; GUNDT, S. Development of microorganisms during storage of wet brewery waste under aerobic and anaerobic conditions. Revista Brasileira de Zootecnia, Brasília, DF v. 41, n. 1, p. 188-193, 2012.

TILLEY, J. M. A.; TERRY R. A. A two stage technique for the in vitro digestion of forage crops J. Br. Grassl. Soc., v. 18, pp. 104-111, 1963. http://dx.doi.org/10.1111/j.1365-2494.1963.tb00335.x 
TOMICH, T. R.; RODRIGUES, J. A. S.; GONCALVES, L. C.; TOMICH, R. G. P.; CARVALHO, A. U. Potencial forrageiro de cultivares de girassol produzidos na safrinha para ensilagem. Arquivo Brasileiro de Medicina Veterinária e Zootecnia, Belo Horizonte, MG v. 55, n. 6, p. 756-762, 2003.

TOMICH, T. R. ; RODRIGUES, J. A. S. ; TOMICH, R. G. P. ; GONÇALVES, L. C. ; BORGES, I. . Potencial forrageiro de híbridos de sorgo com capim-sudão. Arquivo Brasileiro de Medicina Veterinária e Zootecnia, Belo Horizonte, MG v. 56, n. 2, p. 258-263, 2004.

TOMICH, T. R.; TOMICH, R. G. P; GONÇALVES, L. C; BORGES, I; RODRIGUES, J. A. S. Valor nutricional de híbridos de sorgo com capim-sudão em comparação ao de outros volumosos utilizados no período de baixa disponibilidade das pastagens. Arquivo Brasileiro Medicina Veterinária e Zootecnia, Belo Horizonte, MG v. 58, n. 6, p. 1249-1252, 2006.

VALADARES FILHO, S. C. Nutrição, avaliação de alimentos e tabelas de composição de alimentos para bovinos. In: REUNIÃO ANUAL DA SOCIEDADE BRASILEIRA DE ZOOTECNIA, 37. Viçosa, 2000. Anais.Viçosa, MG: SBZ, 2000.

VALADARES FILHO, S. C.; SILVA, F. F.; ROCHA JUNIOR, V. R.; CAPPELLE, E. R. Tabelas de Composição de Alimentos e Exigências Nutricionais para Bovinos no Brasil. In: BITTENCOURT, A. et al.. (Org.). Anais do II Simpósio de Produção de Gado de Corte. 20.ed.Viçosa: Suprema Gráfica e Editora Ltda, v. 1, p. 291-358. 2001.

VAN SOEST, P. J. Nutritional ecology of the ruminant. 2 ed., London: Comstock Publishing Associates. 1994. 476p.

VAN SOEST, P. J., ROBERTSON, J. B., LEWIS, B. A. Methods for dietary fiber, neutral detergent fiber, and non starch polyssacharides in relation to animal nutrition. Journal Dairy Science, 1800 Oak St. Sul v. 74, n. 10, p. 3583-3597. 1991.

ZAMBOM, M. A.; ALCALDE, C. R.; SILVA, K. T.; MACEDO, F. A. F.; RAMOS, C. E. C. O. ; PASSIANOTO, G. O. Desempenho e digestibilidade dos nutrientes de rações com casca do grão de soja em substituição ao milho para cabras Saanen, em pré-parto e lactação. Revista Brasileira de Zootecnia, Brasília, DF v. 37, p. 1311-1318, 2008. 